\title{
Deficiency of the Microglial Receptor CX3CR1 Impairs Postnatal Functional Development of Thalamocortical Synapses in the Barrel Cortex
}

\author{
Maki Hoshiko, ${ }^{1,2,3,4 *}$ Isabelle Arnoux, ${ }^{1,2,3 *}$ Elena Avignone, ${ }^{1,2,3,5}$ Nobuhiko Yamamoto, ${ }^{4}$ and Etienne Audinat ${ }^{1,2,3}$ \\ ${ }^{1}$ Institut National de la Santé et de la Recherche Médicale, U603, 75006 Paris, France, ${ }^{2}$ Centre National de la Recherche Scientifique (CNRS) UMR 8154, 75006 Paris, \\ France, ${ }^{3}$ Laboratoire de Neurophysiologie et Nouvelles Microscopies, Paris Descartes University, 75006 Paris, France, ${ }^{4}$ Graduate School of Frontier Biosciences, \\ Osaka University, Suita, Osaka 565-0871, Japan, and ${ }^{5}$ Interdisciplinary Institute for Neuroscience, CNRS UMR 5297, Bordeaux University, 33077 Bordeaux, France
}

Accumulative evidence indicates that microglial cells influence the normal development of brain synapses. Yet, the mechanisms by which these immune cells target maturating synapses and influence their functional development at early postnatal stages remain poorly understood. Here, we analyzed the role of CX3CR1, a microglial receptor activated by the neuronal chemokine CX3CL1 (or fractalkine) which controls key functions of microglial cells. In the whisker-related barrel field of the mouse somatosensory cortex, we show that the recruitment of microglia to the sites where developing thalamocortical synapses are concentrated (i.e., the barrel centers) occurs only after postnatal day 5 and is controlled by the fractalkine/CX3CR1 signaling pathway. Indeed, at this developmental stage fractalkine is overexpressed within the barrels and CX3CR1 deficiency delays microglial cell recruitment into the barrel centers. Functional analysis of thalamocortical synapses shows that CX3CR1 deficiency also delays the functional maturation of postsynaptic glutamate receptors which normally occurs at these synapses between the first and second postnatal week. These results show that reciprocal interactions between neurons and microglial cells control the functional maturation of cortical synapses.

\section{Introduction}

Microglial cells (MGCs) derive from myeloid progenitors born in the yolk sac and colonize the CNS during embryonic and early postnatal life (Pont-Lezica et al., 2011). Accumulating evidence indicates that, in addition to their roles in CNS diseases, MGCs also influence brain development. In humans, description of the spatiotemporal organization of microglia in the embryonic and fetal CNS suggests that these cells play active roles in developmental processes (Verney et al., 2010). In rodents, experimental evidence shows that MGCs contribute to developmentally regulated neuronal apoptosis but also to synapse pruning (Mallat et

\section{Received March 9, 2012; revised Aug. 21, 2012; accepted Aug. 29, 2012}

Author contributions: M.H., I.A., N.Y., and E. Audinat designed research; M.H., I.A., and E. Avignone performed research; M.H., I.A., and E. Audinat analyzed data; M.H., I.A., E. Avignone, N.Y., and E. Audinat wrote the paper.

This work was supported by Inserm, CNRS, The Agence Nationale de la Recherche (ANR 2010 BLAN 141901), the Région Ile-de-France (NeRF), the Collège Doctoral Franco-Japonais, Kakenhi 20021018, and a Grant-in-Aid for Scientific Research on Innovative Areas "Mesoscopic Neurocircuitry" (No.23115102) from the Ministry of Education, Culture, Sports, Science and Technology of Japan and the Uehara Memorial foundation. Confocal pictures were acquired at the microscopy platform of the Saints Pères University Center. The Audinat lab is affiliated to Paris School of Neuroscience (ENP). We thank Nicole Ropert and Alexis Evrard for advice and helpful discussions throughout this study, Serge Charpak and Céline Bidoret for critical reading of an earlier version of the manuscript, Patricia Gaspar for advice on initial experiments, Jérôme Lecoq for computer programs, and Françoise Levavasseur for her help with some experiments and with the breeding of mouse colonies.

*M.H. and I.A. contributed equally to the work.

Correspondence should be addressed to Etienne Audinat, Laboratoire de Neurophysiologie et Nouvelles Microscopies, INSERM U603, CNRS UMR 8154, Université Paris Descartes, 45, rue des Saints-Pères, 75006 Paris, France. E-mail: etienne.audinat@parisdescartes.fr.

M. Hoshiko's present address: Department of Neurophysiology, School of Medicine, Keio University, Shinjuku-ku, Japan.

DOI:10.1523/JNEUROSCI.1167-12.2012

Copyright $\odot 2012$ the authors $\quad 0270-6474 / 12 / 3215106-06 \$ 15.00 / 0$ al., 2005; Pont-Lezica et al., 2011; Schlegelmilch et al., 2011; Tremblay et al., 2011).

In the diseased adult CNS, several signaling pathways control the recruitment of microglia at sites of compromised homeostasis (Hanisch and Kettenmann, 2007; Ransohoff and Perry, 2009). During normal CNS development, the signaling mechanisms by which MGCs reach and influence their neuronal targets at the right time remain poorly understood. Fractalkine (or CX3CL1) is one of the signaling molecules which can instruct microglia on neuronal and synaptic maturation. This chemokine is expressed by neurons; its receptor CX3CR1 is only expressed by MGCs and controls their migration and functions (Harrison et al., 1998; Maciejewski-Lenoir et al., 1999; Cardona et al., 2006; Ruitenberg et al., 2008; Liang et al., 2009; Paolicelli et al., 2011). To explore further the role of MGCs on neuronal network maturation, we analyzed the impact of CX3CR1 deficiency on the development of the barrel field of the mouse somatosensory cortex. Indeed, the structural and functional development of the whisker pad representation in layer 4 of the cortex follows a precise and well documented pattern. Briefly, the first barrel-like structures emerge at postnatal day $4(\mathrm{P} 4)$ from the convergence of thalamocortical axons (TCAs) conveying information from a single whisker and terminating in cortical layer 4 . This initial step is followed by the aggregation of layer 4 neuronal cell bodies in the barrel walls around TCA clusters and the reorientation of their dendrites toward the barrel centers. In parallel, several functional parameters of thalamocortical synapses evolve between $\mathrm{P} 4$ and the end of the second postnatal week (López-Bendito and Molnár, 2003; Daw et al., 2007; Inan and Crair, 2007). We reasoned that this precise 
spatiotemporal pattern of development should help deciphering the roles of MGCs in neuronal circuit development. We found that the fractalkine/CX3CR1 signaling pathway controls MGC entry into the barrel centers and the proper functional maturation of thalamocortical synapses.

\section{Materials and Methods}

Animals. All experiments followed European Union and institutional guidelines for the care and use of laboratory animals (council directive 86/609EEC). In few experiments heterozygous CX3CR1 ${ }^{+/ e G F P}$ mice of either sex were obtained by crossing CX3CR1 eGFP/eGFP (Jung et al., 2000) with wild-type C57BL/6J mice (Janvier). However, most experiments were performed on homozygous (i.e., knock-out) and heterozygous animals from same littermates by crossing CX3CR $1^{\text {eGFP/eGFP }}$ and CX3CR $1^{+/ \text {eGFP }}$ mice. Mice were genotyped using the primers $5^{\prime}$-TTCA CGTTCGGTCTGGTGGG-3'; 5'-GATCACTCTCGGCATGGACG-3' and $5^{\prime}$-TTCACGTTCGGTCTGGTGGG-3'; 5'-GGTTCCTAGTGGAG CTAGGG-3') producing 970- and 1010-bp-long fragments for wild-type and mutant alleles, respectively.

Immunohistochemistry. Urethane ( $2 \mathrm{~g} / \mathrm{kg})$-anesthetized mice were perfused transcardially with $4 \%$ paraformaldehyde in $0.1 \mathrm{M}$ phosphate buffer, followed by overnight fixation of the brains (flattened for tangential sections). Fifty-micrometer-thick coronal or tangential sections were preincubated for $1 \mathrm{~h}$ at room temperature (RT) in PBS containing 2\% bovine serum albumin (Sigma-Aldrich) and 0.3\% Triton X-100 (SigmaAldrich) and then for $48 \mathrm{~h}$ at $4^{\circ} \mathrm{C}$ with primary antibodies against the serotonin transporter (5-HTT; 1:1000; rabbit polyclonal; Calbiochem), the glutamate vesicular transporter (VGluT2; 1:1000; guinea pig polyclonal; Millipore Bioscience Research Reagents), or the microgliaspecific marker Ibal (1:1000, rabbit polyclonal, Wako Chemicals). After washing, sections were incubated at RT with secondary antibodies Alexa Fluor546 (anti-rabbit IgG 1:300; Invitrogen) or Alexa Fluor633 (antiguinea pig IgG 1:200; Invitrogen) and with TO-PRO-3 (1:1000; Invitrogen). For CX3CL1 immunostaining, sections were incubated for $1 \mathrm{~h}$ with $5 \%$ normal donkey serum and $0.5 \%$ Triton X-100 at RT, then $48 \mathrm{~h}$ at $4^{\circ} \mathrm{C}$ with CX3CL1 antibodies (1:50; goat polyclonal; R\&D Systems). After 5 washes, sections were incubated for $48 \mathrm{~h}$ at $4^{\circ} \mathrm{C}$ with Cy3 (anti-goat IgG 1:200; Millipore Bioscience Research Reagents). Sections were mounted with Vectashield (Vector Labs).

Quantitative analysis. Image program was used to analyze confocal images spanning $30 \pm 6 \mu \mathrm{m}$. We used tangential sections through layer 4 to count the number of microglial cells inside and outside TCA clusters immunostained for 5-HTT or VGluT2. The periphery of each barrel was defined by the borders of the neighboring TCA clusters. The numbers of MGCs inside and outside TCA clusters were counted. Six barrels of rows $\mathrm{B}$ and $\mathrm{C}$ were usually considered for each animal. Data are presented as mean \pm SEM Statistical evaluation was performed with one-way ANOVA test followed by Mann-Whitney $U$ test (GraphPad InStat).

Electrophysiology. Thalamocortical (TC) slices $(400 \mu \mathrm{m})$ from P5 to P33 mice were prepared as previously described (Laurent et al., 2002) in an ice-cold solution containing (in $\mathrm{mm}$ ): 215 sucrose, $2.5 \mathrm{KCl}, 1.25$ $\mathrm{NaH}_{2} \mathrm{PO}_{4}, 26 \mathrm{NaHCO}_{3}, 20$ glucose, 5 pyruvate, $1 \mathrm{CaCl}_{2}$ and $7 \mathrm{MgCl}_{2}$, bubbled with carbogene, $\mathrm{pH}$ 7.4, $310 \mathrm{mOsm}$. Slices were then incubated for $30-45 \mathrm{~min}$ at $33^{\circ} \mathrm{C}$, and subsequently maintained at RT $\left(21-24^{\circ} \mathrm{C}\right)$ in a solution containing $126 \mathrm{~mm} \mathrm{NaCl}$ instead of sucrose, $1 \mathrm{~mm} \mathrm{MgCl}$, and $2 \mathrm{mM} \mathrm{CaCl}_{2}$. Individual slices were transferred to a recording chamber perfused with the same solution at $4 \mathrm{ml} / \mathrm{min}$ at RT. Whole-cell recordings were performed from layer 4 neurons with pipettes (3-5 M $\Omega$ ) filled with a solution containing (in mM): $125 \mathrm{CsMeSO}_{3}, 10$ HEPES, 10 EGTA, 8 TEA-Cl, 5 4-AP, 0.4 GTP-Na, 4 ATP-Na, $1 \mathrm{CaCl}_{2}$ and $1 \mathrm{MgCl}_{2}$ ( $\mathrm{pH} 7.3,290 \mathrm{mOsm}$ ). Biocytin was included in the intracellular solution in 10 experiments and revealed a typical morphology of layer 4 multipolar spiny stellate cells, i.e., multipolar soma from which extended 3-6 spiny dendrites. Voltage-clamp recordings were performed using an Axopatch 200B (Molecular Devices). Currents were low-pass filtered at 1 $\mathrm{kHz}$, collected at a frequency $10 \mathrm{kHz}$, and analyzed off-line using PClamp 9 (Molecular Devices). During recording, the series resistance $\left(R_{\mathrm{s}}\right)$ was not compensated and was monitored continuously. Recordings were discarded if $R_{\mathrm{s}}$ increased by $>20 \%$. All potentials were corrected for a junction potential of $-8 \mathrm{mV}$. Synaptic responses were evoked with a stainless steel bipolar microelectrode $(100 \mu \mathrm{m}$ tip diameter, $250 \mu \mathrm{m}$ intertip distance; Rhodes Medical Instruments) connected to stimulus isolation unit (Iso-stim 01D; npi Electronic) and placed in the internal capsule near the thalamus border. The intensity of stimulation $(0.2 \mathrm{~ms}$ and $0.05 \mathrm{~Hz}$ ) was adjusted according to the protocol of minimal stimulation described by Laurent et al. (2002). The amplitude and time constants of EPSCs were quantified from the average of 15-20 consecutives responses. EPSC decays were fitted with a double exponential function $\left[A_{1} \exp \left(t / \tau_{1}\right)+A_{2} \exp \left(t / \tau_{2}\right)\right]$ and the weighted time constant of the decay was defined as $\tau_{\text {weighted }}=\left[\tau_{1} \times A_{1} /\left(A_{1}+A_{2}\right)\right]+\left[\tau_{2} \times A_{2} /\left(A_{1}+A_{2}\right)\right]$. To determine the paired-pulse ratio of TC EPSCs, paired stimulations were evoked at $-70 \mathrm{mV}$ with an interval of $60 \mathrm{~ms}$ and the ratio of the second over the first EPSC was measured on the averaged response. When outward currents were evoked at $0 \mathrm{mV}$, gabazine (Gbz; SR-95531; Ascent Scientific) was added to the bath to inhibit $\mathrm{GABA}_{\mathrm{A}}$ receptors. The following drugs were also applied in the perfusion: $\mathrm{D}-(-)-2$-amino-5-phosphonopentanoic acid (D-AP-5) and 2,3-dioxo-6-nitro-1,2,3,4-tetrahydrobenzo[f] quinoxaline-7sulfonamide disodium salt (NBQX; Ascent Scientific) and Ro256981 (Tocris Bioscience). Values are presented as mean \pm SEM. Statistical significance was tested with a Mann-Whitney $U$ test or unpaired $t$ tests (GraphPad InStat). Throughout the text $n$ refers to the number of cells and $N$ to the number of animals.

\section{Results}

\section{Fractalkine/CX3CR1 signaling controls microglial cell entry into the barrel centers}

We first examined the distribution of microglia in layer 4 of the developing barrel cortex of CX3CR $1^{+/ e G F P}$ mice in which MGCs are the only fluorescent cells in the healthy brain (Jung et al., 2000). In tangential sections through layer 4 at P4 and P5, the first stages at which barrels can be identified (Rebsam et al., 2002), we observed that MGCs remained mostly outside clusters of TCAs (Fig. 1A) which occupy the barrel hollows (Fig. 1C). The invasion of TCA clusters by MGCs started at P6 and became more evident at P7 (Fig. $1 A$ ). The ratio of the number of microglia inside and outside TCA clusters (I/O ratio) increased progressively between P5 and P9 (Fig. 1D) and was closed to unity in the barrel field of adult mice $(0.93 \pm 0.10 ; N=3 ; \mathrm{P} 60-\mathrm{P} 70)$. A similar developmental pattern was observed in CX3CR $1^{+/+}$mice with almost no microglia entering TCA clusters before $\mathrm{P} 6$ and an I/O ratio at P7 of $0.39 \pm 0.19$ (Fig. $1 C ; N=3$ ) similar to that observed in CX3CR $1^{+/ \text {eGFP }}$ mice (Fig. $1 D ; p=0.28$ ).

We then tested whether CX3CL1/R1 signaling influences this precise spatiotemporal distribution of MGCs distribution in the developing barrel field by analyzing CX3CR $1^{\text {eGFP/eGFP }}$ mice in which MGCs do not express functional fractalkine receptors (Jung et al., 2000). Although MGCs were also distributed around TCA clusters at P5 (Fig. $1 \mathrm{~B}$ ), there was a significant deficit of

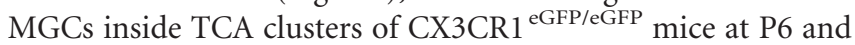
P7 (Fig. $1 B, D$ ). This deficit of MGC entry into the TCA clusters of CX3CR1 $1^{\text {eGFP/eGFP }}$ mice was transient and there was no difference in the $\mathrm{I} / \mathrm{O}$ ratio between heterozygous and homozygous mice at P9 (Fig. 1D). In contrast with recent observations in the developing hippocampus (Paolicelli et al., 2011), we did not observed an overall lower density of MGCs in layer 4 of the somatosensory cortex of these mice compared with that of CX3CR $1^{+/ \text {eGFP }}$ animals (Fig. $1 E, F$ ). This suggests that fractalkine favors the recruitment of MGCs at maturating synapses rather than controls the overall density of these cells in the cortex. In agreement with this hypothesis, we found that fractalkine immunoreactivity labels the barrels of the somatosensory cortex between P5 and P7 (Fig. 1G; $N=3$ ). Before the formation of the barrels, at P3, fractalkine immunostaining was more diffuse and 

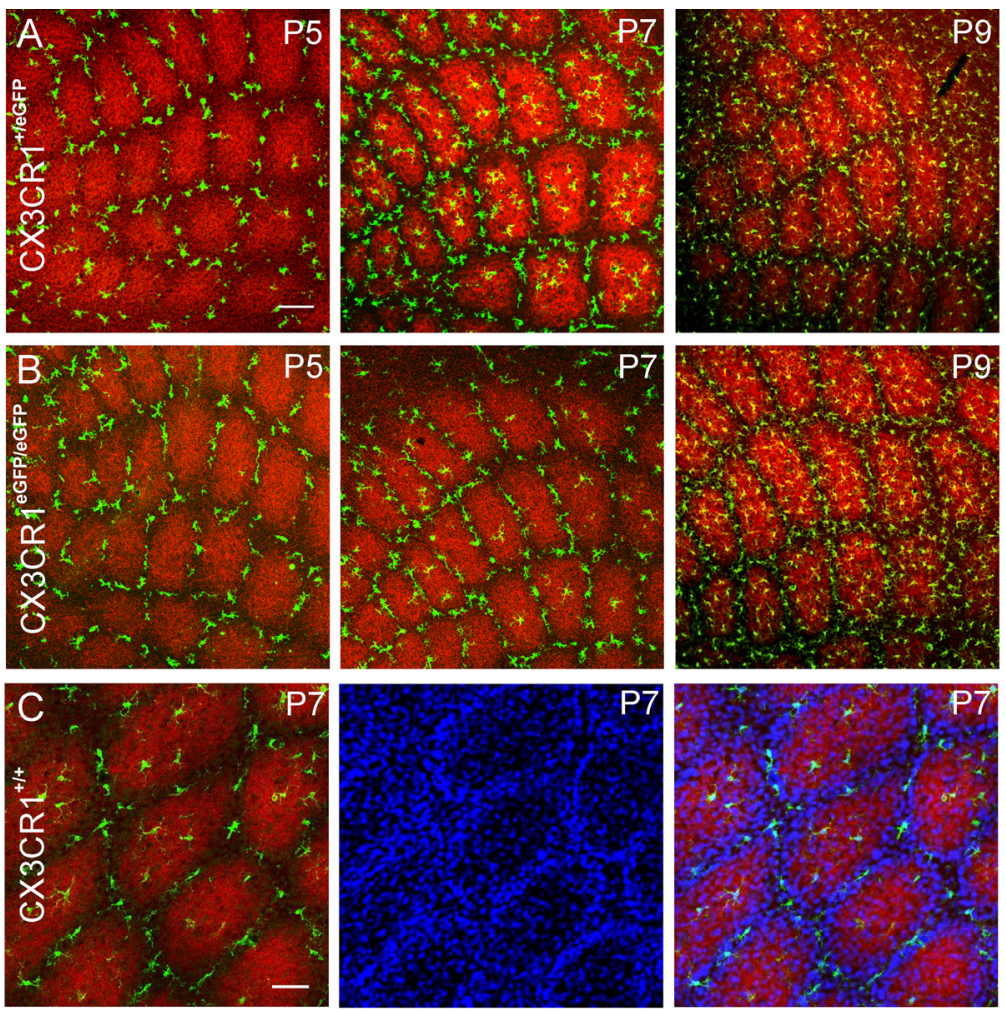

D
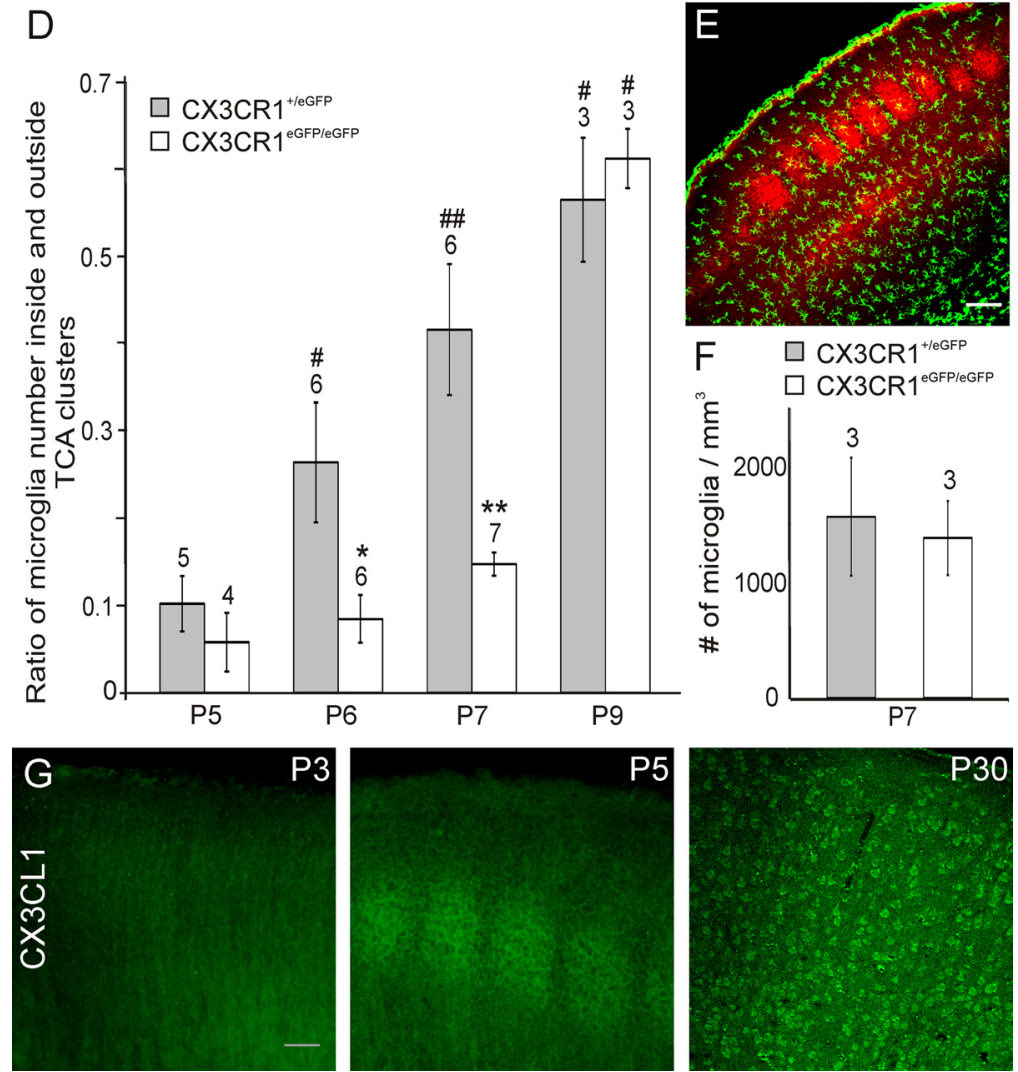

Figure 1. $\quad \mathrm{CX} 3 \mathrm{CL} 1 / \mathrm{R} 1$ signaling controls the entry of microglia into TCA clusters. $A, B$, Merge confocal images of tangential sections through layer 4 showing TCA (red, anti-5-HTT) and fluorescent microglia (green) of the barrel field of P5, P7, and PS CX3CR1 ${ }^{+/ \text {eGFP }}(\boldsymbol{A})$ and $\mathrm{CX} 3 \mathrm{CR} 1^{\text {eGFP/eGFP }}(\boldsymbol{B})$ mice. $C$, Confocal images of a tangential section through layer 4 of a P7 CX3CR1 ${ }^{+/+}$ mouse showing microglia (green, anti-lba1), TCAs (red, anti-VGlut2) and nuclei (blue, T0-PRO-3). $\boldsymbol{D}$, Comparison of the ratio of microglia number inside and outside TCA clusters in CX3CR1 ${ }^{+/ \text {eGFP }}$ and CX3CR1 ${ }^{\text {GFP/eGFP }}$ mice. ${ }^{*} p<0.02{ }^{* *} p<0.01$ between CX3CR1 + /eGFP and CX3CR1 ${ }^{\text {eGFP/eGFP }}$ mice; ${ }^{\#} p<0.05{ }^{\# \#} p<0.01$ between $P 5$ and other ages; Mann-Whitney $U$ test. $E$, Coronal section of the barrel cortex of a P7 CX3CR1 ${ }^{\text {eGFP/eGFP }}$ used to count microglial cells (green) in layer 4 (red, TCAs, anti-5-HTT). $\boldsymbol{F}$

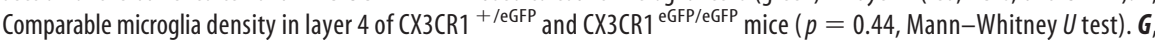

did not allow the identification of the barrels $(N=2)$ whereas in the adult cortex individual cells were immunostained in all cortical layers $(N=2$; Fig. $1 G)$.

\section{Impaired functional maturation of thalamocortical synapses in CX3CR1 deficient mice}

We then asked whether altered MGC development in the barrel field of CX3CR1 $1^{\text {eGFP/eGFP }}$ mice was associated with modifications of the functional maturation of thalamocortical synapses. The proportion of postsynaptic AMPA receptors (AMPARs) increases at these synapses between the first and the second postnatal week, leading to an increase of the ratio of AMPAR- to NMDA receptor (NMDAR)-mediated synaptic currents (AMPAR/NMDAR ratio) (Daw et al., 2007; Inan and Crair, 2007). We thus studied postsynaptic currents evoked by minimal stimulations of TCAs in layer 4 neurons in thalamocortical acute slices of the barrel cortex (Fig. $2 A, B$; see Materials and Methods). The peaks of the fast AMPAR-mediated and of the slow NMDAR-mediated components of the EPSCs were measured at holding potentials of $-70 \mathrm{mV}$ and $+40 \mathrm{mV}$, respectively (Fig. 2E). As expected, the AMPAR/ NMDAR ratio gradually increased in CX3CR $1^{+/ \text {eGFP }}$ mice of P5 $(N=5$, the number of cells $n$ is given in Fig. 2G), P7 $(N=10)$ and $\mathrm{P} 9(N=17$; Fig. $2 F)$. At this latter stage, the AMPAR/NMDAR ratio of CX3CR $1^{+/ \text {eGFP }}$ mice $(0.75 \pm 0.09)$ was not significantly different from that of CX3CR $1^{+/+}$mice $(0.84 \pm 0.12 ; n=9,3$ animals). In contrast, the AMPAR/ NMDAR ratio at thalamocortical synapses of CX3CR1 $1^{\text {eGFP/eGFP }}$ mice did not change significantly over the same developmental window (Fig. $2 F$ ) with mean values remaining below 0.5 at $\mathrm{P} 5(N=3)$, P7 $(N=5)$, and P9 $(N=6$; Fig. $2 G)$. Consequently, the AMPAR/NMDAR ratio at P9 was significantly lower in CX3CR $1{ }^{\text {eGFP/eGFP }}$ than in CX3CR 1 +/eGFP mice (Fig. 2G). The paired-pulse depression, which reflects mostly presynaptic properties, did not differ between CX3CR $1^{+/ \mathrm{eGFP}}$ and CX3CR $1^{\mathrm{eGFP} / \mathrm{eGFP}}$ mice over the same developmental window (Fig. 2C,D;N>3 animals in each case).

Postnatal development of CX3CL1 (fractalkine) immunoreactivity in coronal sections of the mouse somatosensory cortex. Scale bars: $\boldsymbol{A}, \boldsymbol{E}, 100 \mu \mathrm{m} ; \boldsymbol{C}, 50 \mu \mathrm{m} ; \boldsymbol{G}, 200 \mu \mathrm{m}$. Numbers above bar histograms refer to animal numbers. 

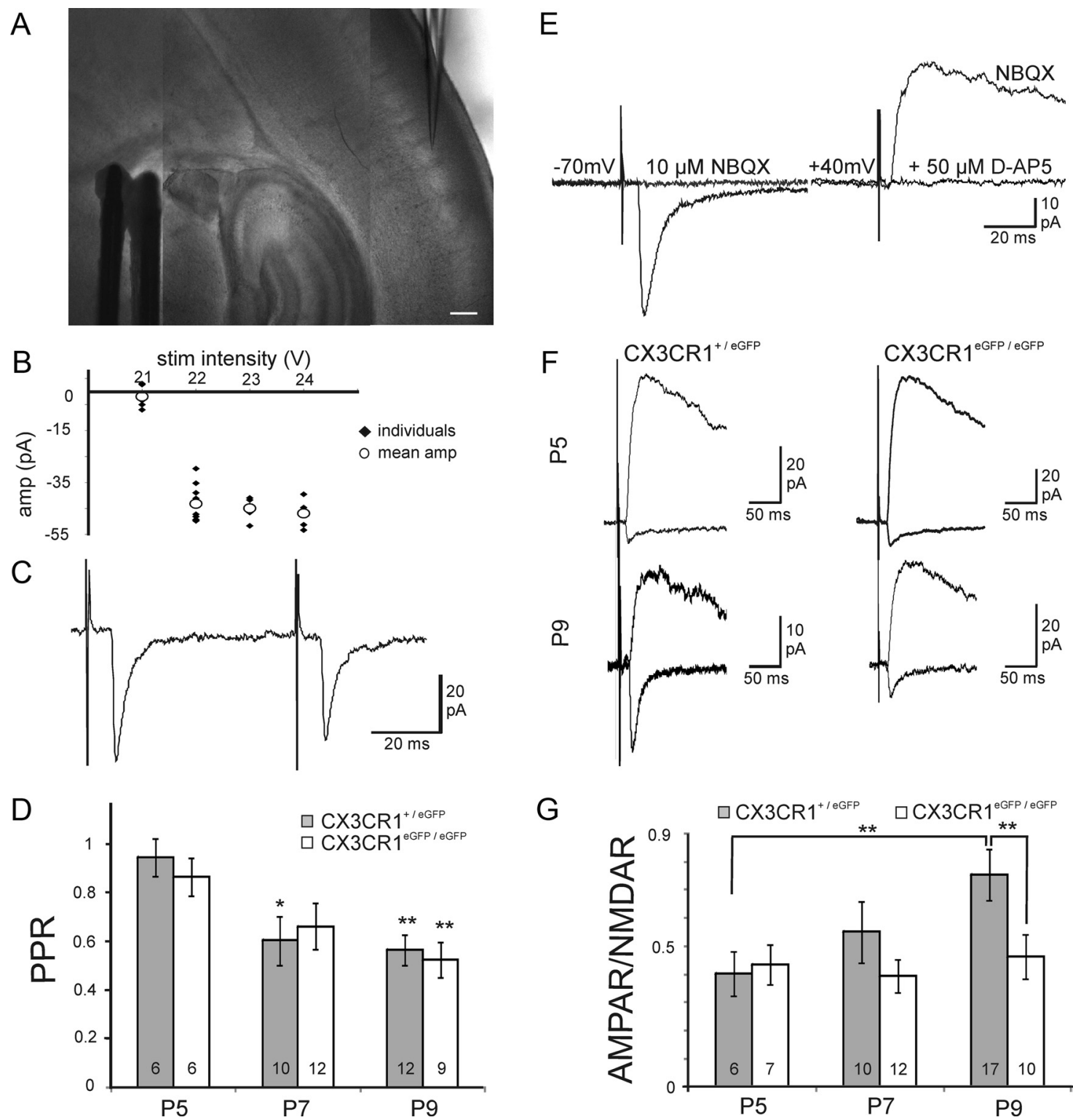

Figure 2. CX3CR1 deficiency impairs the functional maturation of thalamocortical synapses. $A$, DIC image of a P7 thalamocortical slice with the recording pipette in a barrel and the bipolar stimulating electrode in the internal capsule. Scale bar, $200 \mu \mathrm{m}$. $\boldsymbol{B}$, Peak amplitude of individual (black dots) and mean (white circles) thalamocortical EPSCs plotted as a function of the stimulation intensity for the determination of the minimal stimulation (22 V in this example). $\boldsymbol{C}$, Same cell as in $\boldsymbol{B}$, thalamocortical EPSCs evoked by two stimulations for the determination of the paired-pulse ratio. D, Similar paired-pulse ratios of thalamocortical EPSCS in CX3CR1 ${ }^{+/ e G F P}$ and CX3CR1 ${ }^{\text {GFP/eGFP }}$ mice at P5, P7, and P9. Statistical differences between P5 and other ages within each genotype are indicated. $\boldsymbol{E}$, Effect of NBQX and D-AP-5 on thalamocortical EPSCs evoked in a P9 neuron. $\boldsymbol{F}$, AMPAR- and NMDAR-mediated EPSCS in layer 4 neurons of P5 and P9 CX3CR1 + /eGFP and CX3CR1 ${ }^{\text {eGFP/eGFP }}$ mice. G, Comparison of the AMPAR/NMDAR ratio for P5, P7, and P9 CX3CR1 ${ }^{+/ \text {eGFP }}$ and CX3CR $1{ }^{\text {eGFP/eGFP }}$ mice. Each trace is an average of $15-20$ individual sweeps. ${ }^{*} p<0.05,{ }^{* *} p<$ 0.01 (unpaired $t$ test with Welch correction).

Postsynaptic NMDARs at thalamocortical synapses contains predominantly GluN2B subunits during the first postnatal week and GluN2A at the end of the second week. To test whether this developmental maturation process occurs normally in CX3CR1 $1^{\text {eGPP/eGFP }}$ mice, we estimated the relative contribution of GluN2B-containing receptors in NMDAR-mediated synaptic currents of layer 4 neurons of P9-P10 mice by using the GluN2B selective antagonist Ro256981 (300 nM). The charge of NMDARmediated responses was reduced by $21.48 \pm 5.38 \%(N=7)$ and by $44.32 \pm 5.60 \%(N=5)$ in CX3CR $1^{+/ \mathrm{GFP}}$ and in CX3CR1 ${ }^{\text {eGFP/eGFP }}$ mice, respectively (Fig. $3 A, B$ ), indicating that a higher proportion of GluN2B-containing NMDARs were maintained at maturating synapses of CX3CR $1^{\text {eGFP/eGFP. The de- }}$ crease in GluN2B relative contribution during development is associated with faster kinetics of NMDAR-mediated synaptic currents (Daw et al., 2007; Inan and Crair, 2007). Accordingly, the weighted decay time constant of NMDAR-mediated synaptic currents at thalamocortical synapses of CX3CR $1^{+/ e G F P}$ mice decreased from $187.79 \pm 6.29 \mathrm{~ms}$ at P5-P7 $(N=7)$ to $145.42 \pm$ $12.07 \mathrm{~ms}$ at P9-P10 $(N=11$; Fig. $3 C, D)$. In contrast, in CX3CR1 ${ }^{\text {eGFP/eGFP }}$ mice this decay time constant did not change between P5 and P7 (198.69 $\pm 22.15 \mathrm{~ms} ; N=6)$ and P9 and P10 $(197.06 \pm 15.07 \mathrm{~ms} ; N=10 ; p=0.95 ;$ Fig. $3 C, D)$. Consequently, the decay time constant of NMDAR-mediated synaptic responses at P9-P10 was slower in CX3CR1 ${ }^{\text {GFP/eGFP }}$ mice than in CX3CR1 ${ }^{+/ e G F P}$ mice (Fig. 3D). Finally, this impairment in synapse functional maturation in CX3CR1 $1^{\text {eGFP/eGPP }}$ mice was only transient since the decay time constant of NMDAR-mediated 
synaptic currents in P27-P33 animals did not differ between CX3CR $1^{+/ e G F P}(N=$ $8)$ and CX3CR1 $1^{\text {eGFP/eGFP }}(N=4)$ mice (Fig. 3D) and was similar to that of CX3CR $1^{+/+}$animals $(107.71 \pm 8.23 \mathrm{~ms}$; $n=12 ; N=8 ; p>0.5$, unpaired $t$ test with Welch correction). Overall, our results show that CX3CR1 deficiency induced a transient impairment in the maturation of glutamate receptor functional expression at thalamocortical synapses of layer 4 neurons.

\section{Discussion}

Although macrophages are known to influence the development of peripheral organs, the idea that brain resident macrophages could play a role during CNS development is relatively new (Erblich et al., 2011; Pont-Lezica et al., 2011; Schlegelmilch et al., 2011). Our analysis of the developing barrel cortex of CX3CR $1{ }^{\text {eGFP/eGFP }}$ mice indicates that fractalkine signaling controls the recruitment of MGCs at maturating synapse sites and that, in turn, MGCs influence the functional maturation of thalamocortical synapses.

The striking distribution of MGCs around TCA clusters until P5 is in marked contrast with their homogeneous distribution in the cortex of adult animals. It resembles that of microglia around glomeruli of the developing olfactory bulb (Fiske and Brunjes, 2000) and indicates that MGC colonization of layer 4 does not proceed randomly. The reasons why MGCs refrain from entering the barrel hollows before P6 remain to be identified but clearly fractalkine signaling does not control this initial step. Indeed, CX3CR1 deficiency does not affect the initial distribution of MGCs around TCA clusters. Surprisingly, despite the fact that MGC entry within TCA clusters is delayed by $2 \mathrm{~d}$ in CX3CR 1 eGFP/ eGFP mice, the overall number of MGCs present in layer 4 at P7 is not different from that observed in CX3CR $1^{+/ e G F P}$ mice in which MGCs have already invaded TCA clusters at this stage. These results are in apparent contradiction with those of Paolicelli et al. (2011) indicating that fractalkine regulates the overall number of MGCs colonizing the hippocampus. Our results support a more local role of fractalkine in which cellular elements localized within the barrel hollows, possibly thalamic fibers, overexpress the chemokine at P5-P7 and thus favor directed migration of microglia (Harrison et al., 1998; Maciejewski-Lenoir et al., 1999) toward maturating thalamocortical synapses.

Impairment of the AMPAR/NMDAR ratio and of the GluN2B-to-GluN2A developmental switch as those described here during postnatal development of CX3CR $1^{\text {eGFP/eGFP }}$ mice have also been reported in the hippocampus of mice deficient for the microglial immunoreceptor adaptor DAP12 (Roumier et al., 2004). In these mice, however, this modification which results from a transient impairment of microglia-neuron interactions during embryonic life is observed at excitatory synapses of mature animals (Roumier et al., 2008). In contrast, we show here that the kinetics of NMDAR-mediated synaptic responses in
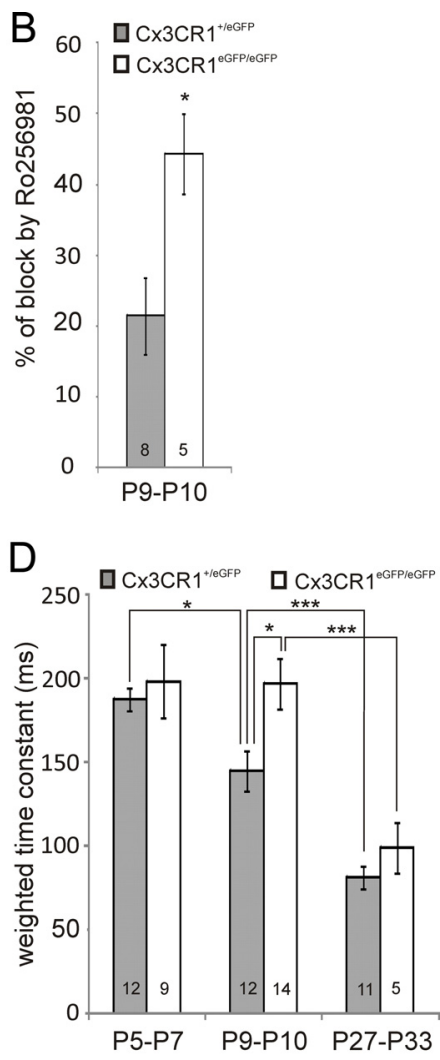

Figure 3. CX3CR1 deficiency impairs the GluN2B to GluN2A developmental switch occurring at thalamocortical synapses between the first and second postnatal week. $A$, Effect of $300 \mathrm{~nm}$ Ro256981 on averaged (15-20 sweeps) NMDAR-mediated EPSCs in neurons of CX3CR1 ${ }^{+/ e G F P}$ (upper traces) and CX3CR1 ${ }^{\text {eGFP/eGFP }}$ (lower traces) mice. B, Summary of Ro256981 effects on

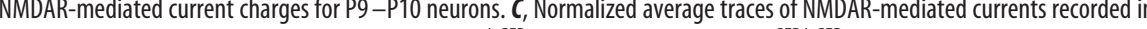
layer 4 neurons of P5 (black) and P10 (red) of CX3CR1 ${ }^{+/ \text {eGFP }}$ (upper traces) and XX3CR1 ${ }^{\text {eGPP/eGFP }}$ (lower traces) mice. D, Comparison of the weighted decay time constant in P5-P7, P9-P10, and adult CX3CR1 ${ }^{+/ \text {eGFP }}$ and CX3CR1 ${ }^{\text {eGFP/eGFP }}$ mice. ${ }^{*} p<0.05,{ }^{* *} p<$ $0.01,{ }^{* * *} p<0.001$ (unpaired $t$ test with Welch correction).

adult CX3CR1 ${ }^{\text {eGFP/eGFP }}$ mice do not differ from those of control mice. Thus, transient impairment in NMDAR maturation seems to results from the transient delayed in MGCs recruitment at thalamocortical synaptic sites. A first hypothesis to explain this observation would be that MGCs, once inside TCA clusters, could contribute to the selection of synapses with a mature signature of their glutamate receptors (Yashiro and Philpot, 2008) by pruning immature synapses through phagocytosis (Paolicelli et al., 2011) in a complement-dependent manner (Schafer et al., 2012). Alternatively, signaling molecules such as interleurkin- $1 \beta$, tumor necrosis factor- $\alpha$ or brain-derived neurotrophic factor, known to be released by microglia, can modulate the expression and the function of glutamate receptors (Beattie et al., 2002; Chao, 2003; Zhang et al., 2010; Zhong et al., 2010). They could therefore influence, directly or indirectly, the functional properties of thalamocortical synapses during development by controlling the expression, targeting, mobility or degradation of glutamate receptors. Several studies on adult rodents have reported that CX3CL1/R1 signaling, probably by controlling the activation state of MGCs, has an impact on functional properties and plasticity of hippocampal glutamate synapses (Ragozzino et al., 2006; Maggi et al., 2011; Rogers et al., 2011). Further studies are thus needed to test whether properties of thalamocortical synapses other than those tested here, such as long-term potentiation, are also controlled by CX3CL1/R1 signaling. Finally, MGCs probably also influence other aspects of barrel maturation such as the rearrangement of dendrites of layer 4 cells and the 
removal of subplate cell neurites which occurs at the end of the first postnatal week (Hoerder-Suabedissen and Molnár, 2012).

\section{References}

Beattie EC, Stellwagen D, Morishita W, Bresnahan JC, Ha BK, Von Zastrow M, Beattie MS, Malenka RC (2002) Control of synaptic strength by glial TNFalpha. Science 295:2282-2285. CrossRef Medline

Cardona AE, Pioro EP, Sasse ME, Kostenko V, Cardona SM, Dijkstra IM, Huang D, Kidd G, Dombrowski S, Dutta R, Lee JC, Cook DN, Jung S, Lira SA, Littman DR, Ransohoff RM (2006) Control of microglial neurotoxicity by the fractalkine receptor. Nat Neurosci 9:917-924. CrossRef Medline

Chao MV (2003) Neurotrophins and their receptors: a convergence point for many signalling pathways. Nat Rev Neurosci 4:299-309. CrossRef Medline

Daw MI, Scott HL, Isaac JT (2007) Developmental synaptic plasticity at the thalamocortical input to barrel cortex: mechanisms and roles. Mol Cell Neurosci 34:493-502. CrossRef Medline

Erblich B, Zhu L, Etgen AM, Dobrenis K, Pollard JW (2011) Absence of colony stimulation factor-1 receptor results in loss of microglia, disrupted brain development and olfactory deficits. PLoS One 6:e26317. CrossRef Medline

Fiske BK, Brunjes PC (2000) Microglial activation in the developing rat olfactory bulb. Neuroscience 96:807-815. CrossRef Medline

Hanisch UK, Kettenmann H (2007) Microglia: active sensor and versatile effector cells in the normal and pathologic brain. Nat Neurosci 10:1387-1394. CrossRef Medline

Harrison JK, Jiang Y, Chen S, Xia Y, Maciejewski D, McNamara RK, Streit WJ, Salafranca MN, Adhikari S, Thompson DA, Botti P, Bacon KB, Feng L (1998) Role for neuronally derived fractalkine in mediating interactions between neurons and CX3CR1-expressing microglia. Proc Natl Acad Sci U S A 95:10896-10901. CrossRef Medline

Hoerder-Suabedissen A, Molnár Z (2012) Morphology of mouse subplate cells with identified projection targets changes with age. J Comp Neurol 520:174-185. CrossRef Medline

Inan M, Crair MC (2007) Development of cortical maps: perspectives from the barrel cortex. Neuroscientist 13:49-61. CrossRef Medline

Jung S, Aliberti J, Graemmel P, Sunshine MJ, Kreutzberg GW, Sher A, Littman DR (2000) Analysis of fractalkine receptor CX(3)CR1 function by targeted deletion and green fluorescent protein reporter gene insertion. Mol Cell Biol 20:4106-4114. CrossRef Medline

Laurent A, Goaillard JM, Cases O, Lebrand C, Gaspar P, Ropert N (2002) Activity-dependent presynaptic effect of serotonin 1B receptors on the somatosensory thalamocortical transmission in neonatal mice. J Neurosci 22:886-900. Medline

Liang KJ, Lee JE, Wang YD, Ma W, Fontainhas AM, Fariss RN, Wong WT (2009) Regulation of dynamic behavior of retinal microglia by CX3CR1 signaling. Invest Ophthalmol Vis Sci 50:4444-4451. CrossRef Medline

López-Bendito G, Molnár Z (2003) Thalamocortical development: how are we going to get there? Nat Rev Neurosci 4:276-289. CrossRef Medline

Maciejewski-Lenoir D, Chen S, Feng L, Maki R, Bacon KB (1999) Characterization of fractalkine in rat brain cells: migratory and activation signals for CX3CR-1-expressing microglia. J Immunol 163:1628-1635. Medline

Maggi L, Scianni M, Branchi I, D’Andrea I, Lauro C, Limatola C (2011) CX(3)CR1 deficiency alters hippocampal-dependent plasticity phenomena blunting the effects of enriched environment. Front Cell Neurosci 5:22. Medline

Mallat M, Marín-Teva JL, Chéret C (2005) Phagocytosis in the developing CNS: more than clearing the corpses. Curr Opin Neurobiol 15:101-107. CrossRef Medline
Paolicelli RC, Bolasco G, Pagani F, Maggi L, Scianni M, Panzanelli P, Giustetto M, Ferreira TA, Guiducci E, Dumas L, Ragozzino D, Gross CT (2011) Synaptic pruning by microglia is necessary for normal brain development. Science 333:1456-1458. CrossRef Medline

Pont-Lezica L, Béchade C, Belarif-Cantaut Y, Pascual O, Bessis A (2011) Physiological roles of microglia during development. J Neurochem 119: 901-908. CrossRef Medline

Ragozzino D, Di Angelantonio S, Trettel F, Bertollini C, Maggi L, Gross C, Charo IF, Limatola C, Eusebi F (2006) Chemokine fractalkine/CX3CL1 negatively modulates active glutamatergic synapses in rat hippocampal neurons. J Neurosci 26:10488-10498. CrossRef Medline

Ransohoff RM, Perry VH (2009) Microglial physiology: unique stimuli, specialized responses. Annu Rev Immunol 27:119-145. CrossRef Medline

Rebsam A, Seif I, Gaspar P (2002) Refinement of thalamocortical arbors and emergence of barrel domains in the primary somatosensory cortex: a study of normal and monoamine oxidase a knock-out mice. J Neurosci 22:8541-8552. Medline

Rogers JT, Morganti JM, Bachstetter AD, Hudson CE, Peters MM, Grimmig BA, Weeber EJ, Bickford PC, Gemma C (2011) CX3CR1 deficiency leads to impairment of hippocampal cognitive function and synaptic plasticity. J Neurosci 31:16241-16250. CrossRef Medline

Roumier A, Béchade C, Poncer JC, Smalla KH, Tomasello E, Vivier E, Gundelfinger ED, Triller A, Bessis A (2004) Impaired synaptic function in the microglial KARAP/DAP12-deficient mouse. J Neurosci 24:11421-11428. CrossRef Medline

Roumier A, Pascual O, Béchade C, Wakselman S, Poncer JC, Réal E, Triller A, Bessis A (2008) Prenatal activation of microglia induces delayed impairment of glutamatergic synaptic function. PLoS One 3:e2595. CrossRef Medline

Ruitenberg MJ, Vukovic J, Blomster L, Hall JM, Jung S, Filgueira L, McMenamin PG, Plant GW (2008) CX3CL1/fractalkine regulates branching and migration of monocyte-derived cells in the mouse olfactory epithelium. J Neuroimmunol 205:80-85. CrossRef Medline

Schafer DP, Lehrman EK, Kautzman AG, Koyama R, Mardinly AR, Yamasaki R, Ransohoff RM, Greenberg ME, Barres BA, Stevens B (2012) Microglia sculpt postnatal neural circuits in an activity and complementdependent manner. Neuron 74:691-705. CrossRef Medline

Schlegelmilch T, Henke K, Peri F (2011) Microglia in the developing brain: from immunity to behaviour. Curr Opin Neurobiol 21:5-10. CrossRef Medline

Tremblay MÈ, Stevens B, Sierra A, Wake H, Bessis A, Nimmerjahn A (2011) The role of microglia in the healthy brain. J Neurosci 31:16064-16069. CrossRef Medline

Verney C, Monier A, Fallet-Bianco C, Gressens P (2010) Early microglial colonization of the human forebrain and possible involvement in periventricular white-matter injury of preterm infants. J Anat 217: 436-448. CrossRef Medline

Yashiro K, Philpot BD (2008) Regulation of NMDA receptor subunit expression and its implications for LTD, LTP, and metaplasticity. Neuropharmacology 55:1081-1094. CrossRef Medline

Zhang R, Sun L, Hayashi Y, Liu X, Koyama S, Wu Z, Nakanishi H (2010) Acute p38-mediated inhibition of NMDA-induced outward currents in hippocampal CA1 neurons by interleukin-1beta. Neurobiol Dis 38:68-77. CrossRef Medline

Zhong Y, Zhou LJ, Ren WJ, Xin WJ, Li YY, Zhang T, Liu XG (2010) The direction of synaptic plasticity mediated by C-fibers in spinal dorsal horn is decided by Src-family kinases in microglia: the role of tumor necrosis factor-alpha. Brain Behav Immun 24:874-880. CrossRef Medline 